\title{
Finite Element Analysis of Distortion-Induced Web Gap Stresses in Multi-I Girder Steel Bridges
}

\author{
Akhrawat Lenwari ${ }^{1, *}$, and Huating Chen ${ }^{2}$ \\ 1 Department of Civil Engineering, Faculty of Engineering, Chulalongkorn University, Phayathai Rd., \\ Pathumwan, Bangkok 10330, Thailand \\ 2 Institute of Road and Bridge Engineering, Department of Civil Engineering, Beijing University of Technology, \\ \#100 PingLeYuan, ChaoYang District, Beijing 100124, China \\ *E-mail: akhrawat.1@chula.ac.th (Corresponding author)
}

\begin{abstract}
Unstiffened girder web gaps at the ends of transverse stiffeners that also serve as diaphragm connection plates are subjected to high local stresses during cyclic out-ofplane distortion. The out-of-plane distortion is mainly caused by the differential deflection between adjacent girders. The purpose of the paper is to investigate the effects of bridge parameters including span length, girder spacing, slab thickness, and girder stiffness on the differential deflection and distortion-induced web gap stresses. Dual-level finite element analyses that consist of both global model and sub-model were performed. The global model was used to investigate the critical truck position and maximum differential deflection between adjacent girders, while the sub-model was used for the critical web gap vertical stress. A base case bridge was a simply supported composite superstructure with three steel I-girders that support two traffic lanes, which is typical for steel bridges over intersections in Bangkok, Thailand. A parametric study was conducted by varying one bridge parameter at a time. The analysis results show that the maximum differential deflections and web gap stresses caused by one-truck loading are higher than those caused by two-truck loading (one truck on each lane). Under one-truck loading, the maximum web gap stress occurs at the interior girder. In addition, both the differential deflections and web gap stresses are primarily dependent on the bridge span length.
\end{abstract}

Keywords: Distortion-induced stress, web gap cracking, parametric study, composite Igirder bridge, finite element method.

ENGINEERING JOURNAL Volume 17 Issue 1

Received 28 June 2012

Accepted 10 September 2012

Published 1 January 2013

Online at http://www.engj.org/

DOI:10.4186/ej.2013.17.1.95 


\section{Introduction}

Steel-concrete composite girders are typically tied together by diaphragms or bracings. These secondary elements are intended to resist lateral load, help distribute traffic loading, and stabilize the girders during construction. The transverse stiffeners connecting the diaphragm and girder normally terminate a few inches from the girder tension flange. The web portion between the transverse stiffener end and girder flange, called the "web gap", is relatively flexible and susceptible to out-of-plane distortion. The web gap cracking has been mainly caused by the secondary stresses due to differential deflection of main girders [1]. Figure 1 shows a typical fatigue crack that initiates at the weld toe at the end of transverse stiffener.

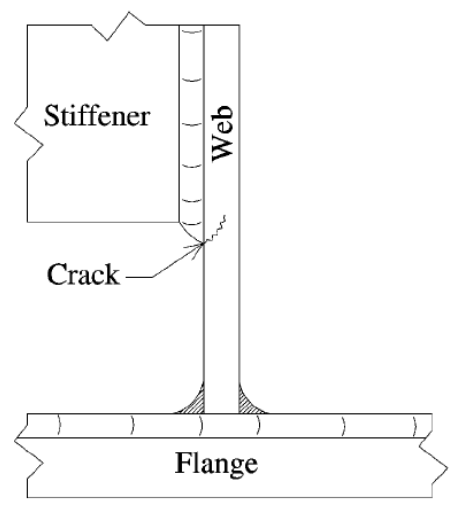

(a)

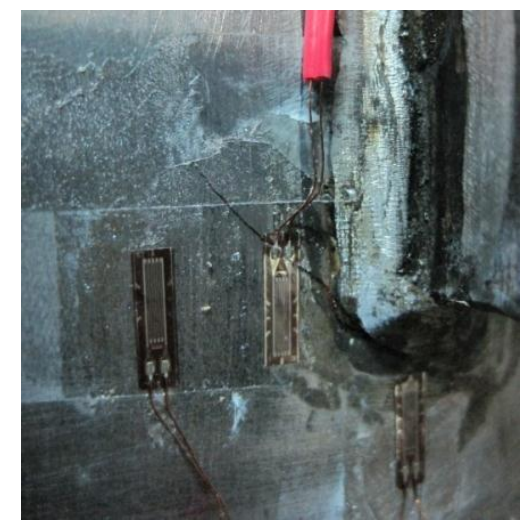

(b)

Fig. 1. Distortion-induced fatigue cracking at stiffener end (a) schematic (b) close-up view of crack.

The AASHTO LRFD Specifications [2] categorizes this type of fatigue cracking as "distortion-induced fatigue" in which the force effect, normally transmitted by a secondary member, may tend to change the shape of, or distort, the cross section of a primary member. However, the out-of-plane distortion-induced stresses are not quantified in the AASHTO design code.

The field measurement data showed that the stress occurring at the connection plate to the web welds was large enough to cause fatigue cracking [3, 4]. In Japan, most cracks occur at the top end of vertical stiffener welded to the tension top flange [5]. These cracks were caused by the secondary stresses due to differential deflection of the main girders and deflection of the reinforced concrete deck by the wheel load of heavy traffic. In the United States, Connor and Fisher [6] reported that 90 percent of the fatigue cracking in steel bridges is related to distortion-induced fatigue.

Analytical models have been proposed to predict the distortion-induced stresses. Based on the linear elasticity, Jajich and Schultz [7] proposed a simple model for predicting the web gap stress, as illustrated in Fig. 2. The web gap was idealized as a beam that is fixed at both ends and undergoes rotation at one end, the maximum moment at the base of web gap is obtained as $M_{w g}=4 E I_{w g} \theta / g$, where $E=$ modulus of elasticity; $I_{w g}=$ moment of inertia of web gap section resisting out-of-plane bending; and $g$ = web gap length. Hence, the maximum stress at the stiffener end of the web gap is $\sigma_{w g}=0.5 M_{w g} t_{w} / I_{w g}$, where $t_{w}$ = web thickness. Combining these expressions and substituting the diaphragm rotation $\theta=\Delta / S$, where $S$ $=$ length of diaphragm or girder spacing and $\Delta=$ differential or relative deflection between adjacent girders, gives the maximum web gap stress as a function of girder differential deflection as follows

$$
\sigma_{w g}=\left(2 E t_{w} / g\right) /(\Delta / S)
$$




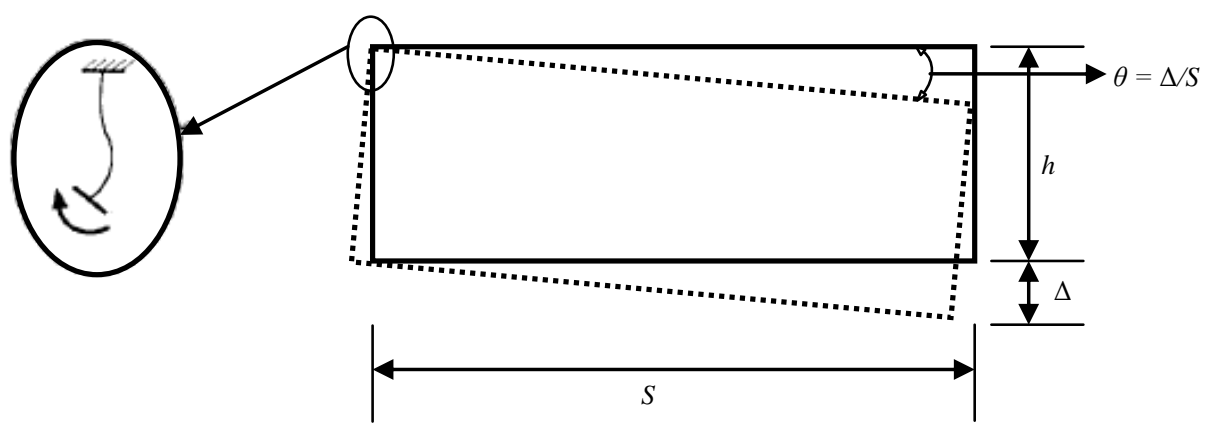

Fig. 2. Schematic representation of web gap and diaphragm rotations [7].

In another model $[1,8]$, the web gap was postulated to behave like short, fixed-fixed beams undergoing a lateral deflection, $\delta$. Figure 3 shows the relationship between the web gap lateral deflection and diaphragm rotation. Therefore, the maximum web gap stress can be calculated as

$$
\sigma_{w g}=\left(3 E t_{w} / g^{2}\right)(h \Delta / S)
$$

where $h=$ diaphragm depth.
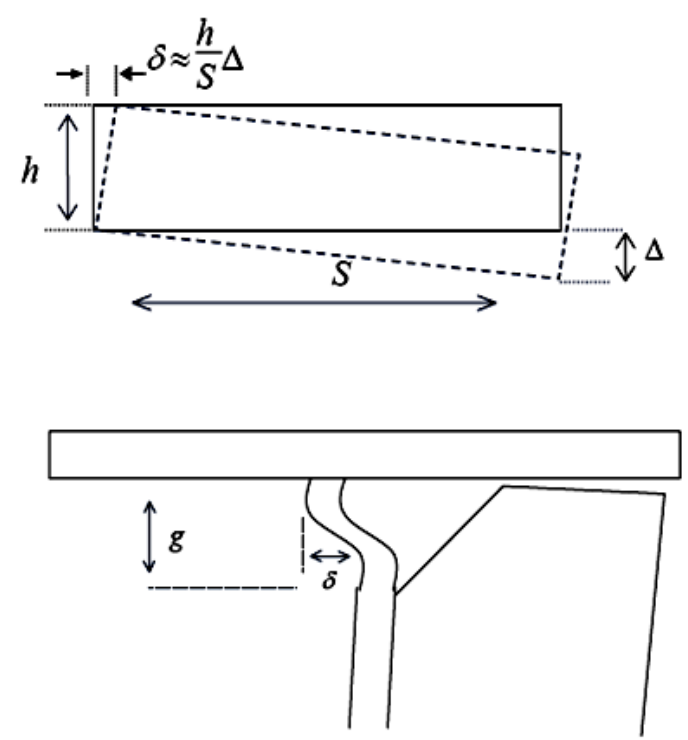

Fig. 3. Lateral web gap deflection caused by diaphragm rotation [1].

According to both analytical models, the differential deflection between adjacent girders is a key variable affecting the distortion-induced stress at web gap. However, the amount of differential deflection cannot be easily predicted due to the interactions between concrete decks, girders, and diaphragms. In addition, the secondary stress at the intersection of stiffener, girder flange, and web is under complex, three dimensional interactions. The local geometry and relative stiffness of the detail is different for individual bridge [9].

Berglund and Schultz [10] investigated the parameters that significantly affect the girder differential deflection using finite element analysis. The results showed that the differential deflection generally increases as the bridge span length, girder spacing, and angle of skew increases.

Jajich et al. [7,11] performed a linear finite element analysis of the diaphragm-stiffener-web connection. A three dimension finite element model was created using SAP2000. The model consisted of two adjacent girders connected by the diaphragm. All portions of steel (web, flanges, diaphragm, and stiffeners) were modeled using the shell element. All dimensions were taken either directly from the bridge or from the 
design plan. The concrete deck was excluded in the model, however the rotational fixity of girder top flanges due to the presence of the deck was assumed.

The truck loads reported in the field tests [7] were applied to a so-called macro model by Li and Schultz [8]. The macro model included the entire bridge and a portion of the bridge surrounding the diaphragm to determine the deformations to be imposed on the bridge micro-model. Deck rotation and diaphragm deflections from macro-model finite element analyses were applied as boundary conditions for the micromodel finite element analyses at the locations where these members were disconnected from the rest of the bridge. The connections between concrete deck and girder top flanges were modeled as rigid elements at closely spaced intervals. The deck boundary was fixed against translation along the edges parallel to the girders. Girder differential deflections and deck rotations from macro-model were applied to the micromodel to determine the web gap movement and stress field.

Since distortion-induced stress is related with differential deflection between adjacent girders due to uneven distribution of live load, the bridge parameters that affect live load distribution are believed to affect the distortion-induced stress. The AASHTO LRFD Specifications [2] define the live load distribution factor for beam and slab bridges with two or more lanes as

$$
L D F=0.075+\left(\frac{S}{2900}\right)^{0.6}\left(\frac{S}{L}\right)^{0.2}\left(\frac{K_{g}}{L t_{s}^{3}}\right)^{0.1}
$$

where $S=$ girder spacing $(\mathrm{mm}) ; L=$ span length $(\mathrm{mm}) ; K_{g}=n\left(I+A e^{2}\right)=$ longitudinal stiffness $\left(\mathrm{mm}^{4}\right) ;$ $t_{s}=$ slab thickness (mm); $n=$ modular ratio between steel and concrete; $I=$ girder stiffness $\left(\mathrm{mm}^{4}\right) ; A=$ girder area $\left(\mathrm{mm}^{2}\right)$; and $e=$ eccentricity between centroids of girder and slab $(\mathrm{mm})$. In Eq. (3), the span length, girder spacing, slab thickness and girder stiffness are the key bridge parameters that affect live load distribution.

The purpose of the paper is to numerically investigate the effects of bridge parameters on the differential deflection and distortion-induced web gap stresses in composite I-girder bridges. The bridge parameters include span length, girder spacing, slab thickness, and girder stiffness. Dual-level finite element analyses which include global model and sub-model are performed. The global model is used to study the differential deflection between adjacent girders, while the sub-model is used for the web gap vertical stress. A base case bridge is idealized from a typical three-girder composite bridge in Bangkok, Thailand. In a parametric study, one bridge parameter is varied, while other parameters have the same values as those in the base case.

\section{Finite Element Model (SAP2000)}

A base case bridge is idealized from an actual simply supported composite I-girder bridge for which the field test data [12] are available for the validation of the finite element model. The base case bridge consists of three composite I-girders equally spaced at $3.0 \mathrm{~m}$, which spans $24 \mathrm{~m}$ and supports two traffic lanes with lane width of $3.0 \mathrm{~m}$. The concrete slab has a thickness of $240 \mathrm{~mm}$. All three girders are built-up wide flange members with dimensions of $1450 \times 450 \times 12 \times 22 \mathrm{~mm}^{4}$. Diaphragms are idealized as I-beam sections of $678 \times 253 \times 12 \times 16 \mathrm{~mm}^{4}$.

In order to capture the distortion-induced stress at web gap accurately while at the same time minimizing computational cost, two levels of linear elastic finite element analysis which consists of global model and sub-model are performed. SAP2000 software package [13] is used to create both global model and sub-model. The global model includes the entire superstructure as shown in Fig. 4(a), which is aimed to investigate the global behavior of the bridge and differential deflection between adjacent girders. The submodel is a more detailed model of a portion of the bridge near diaphragm, as shown in Fig. 4(b), where the web gap stresses will be studied. 


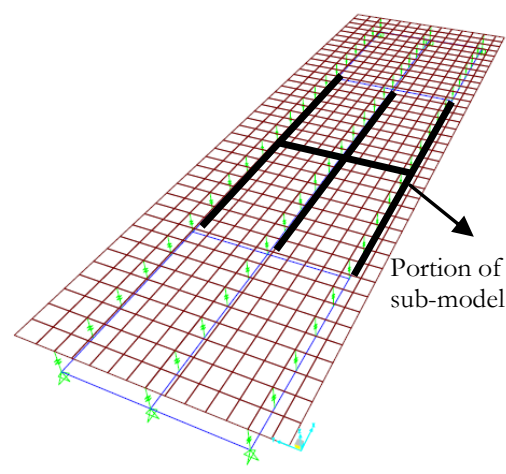

(a)

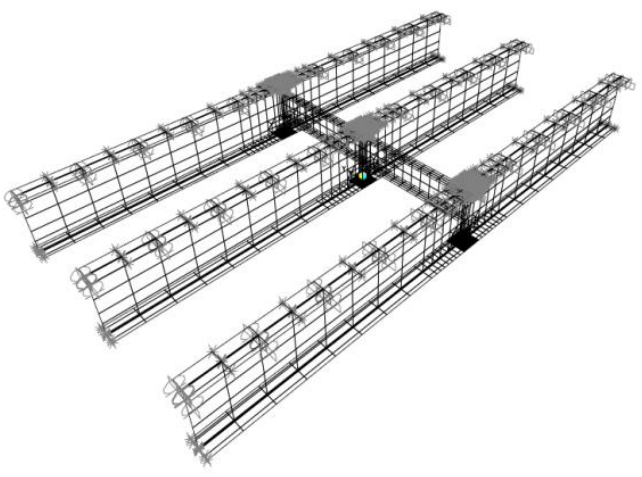

(b)

Fig. 4. Finite element models for base case bridge (a) global model (b) sub-model.

The global model consists of concrete slab, three main girders, and diaphragms at midspan, quarter spans and end spans of the bridge. The moduli of elasticity for structural steel and concrete are taken as $200000 \mathrm{MPa}$ and $24800 \mathrm{MPa}$, respectively. The Poisson ratios for structural steel and concrete are assumed to be 0.3 and 0.2 , respectively. Main girders and diaphragms are idealized as frame elements and the concrete slab is modeled with quadrilateral shell elements. Composite action between steel girders and concrete slab is modeled using rigid links that connect the girder top flange and concrete deck by coupling all degrees of freedom between corresponding nodes. The model is made up of 250 frame elements, 2,240 shell elements, and 243 rigid links.

As a detailed finite element model of the diaphragm-stiffener-web connection, the sub-model in Fig. 4(b) consists of all shell elements. Top flange of girders is free to move in the vertical direction and rotate in the longitudinal direction. In order to simulate the restraining effect of concrete slab, the transverse rotation of top flange nodes is restrained. At the support, the bottom flanges nodes are restrained in the longitudinal and transverse axes of the girder and free to move in longitudinal direction at the roller support. The vertical displacements of girders from global model are applied to the girder top flanges in the submodel. In order to obtain local distortion-induced stresses, the mesh in web gap area is refined and a transition mesh is used to maximize modeling efficiency. A sufficiently refined sub-model consists of 8,638 shell elements. Figure 5 compares the longitudinal bottom flange stresses from the global model with those measured from strain gages at quarter span, midspan, and three quarter span of a base case bridge. The data were obtained under two test trucks that moved along both lanes simultaneously. At midspan, the maximum strain differences are found to be 8,10 and 13 percent for girder G1, G2, and G3, respectively.

As described in Section 1, the main bridge parameters chosen in this study include the bridge span length, girder spacing, slab thickness, and girder stiffness. The range of each parameter refers to the applicability range specified in the AASHTO LDF equation. The bridge span length varies from $18 \mathrm{~m}$ to 36 $\mathrm{m}$, girder spacing varies from $2.1 \mathrm{~m}$ to $3.0 \mathrm{~m}$, and slab thickness varies from $210 \mathrm{~mm}$ to $300 \mathrm{~mm}$. The range of girder stiffness is based on practical range of actual bridges and is varied from $1.0 \times 10^{10} \mathrm{~mm}^{4}$ to $1.7 \times$ $10^{10} \mathrm{~mm}^{4}$. The actual web gap length, i.e., $35 \mathrm{~mm}$, is used for all models in the study.

In order to study the effect of a specific bridge parameter, a parametric study is conducted by varying one parameter while fixing all other parameters at their base bridge values. The superstructure is assumed to remain two lanes and the lane width varies with the girder spacing. Variation in the girder stiffness is accomplished by varying the thickness of web and flange plates while keeping the girder height and flange width the same as the base case. For the four cases of varying girder stiffness, the girder sections are $1450 \times$ $450 \times 10 \times 18 \mathrm{~mm}^{4}, 1450 \times 450 \times 12 \times 22 \mathrm{~mm}^{4}, 1450 \times 450 \times 14 \times 26 \mathrm{~mm}^{4}$, and $1450 \times 450 \times 16 \times 30$ $\mathrm{mm}^{4}$, respectively. Sixteen variations of bridge parameters are modeled in the parametric study as shown in Table 1. 


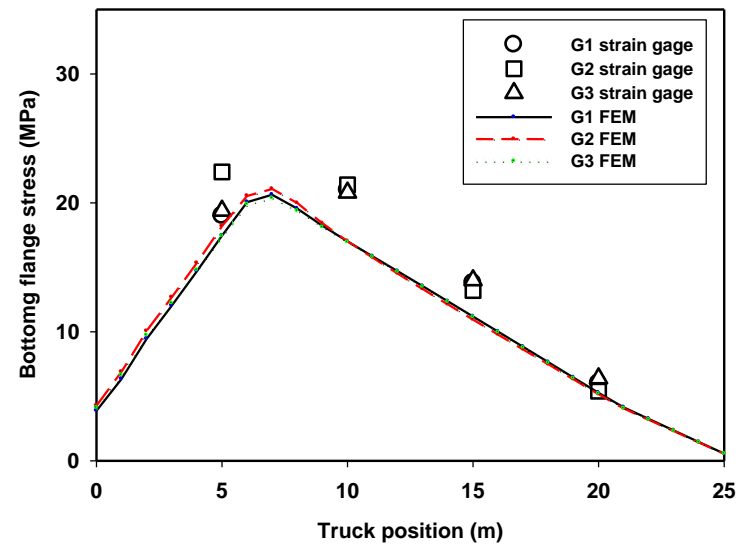

(a)

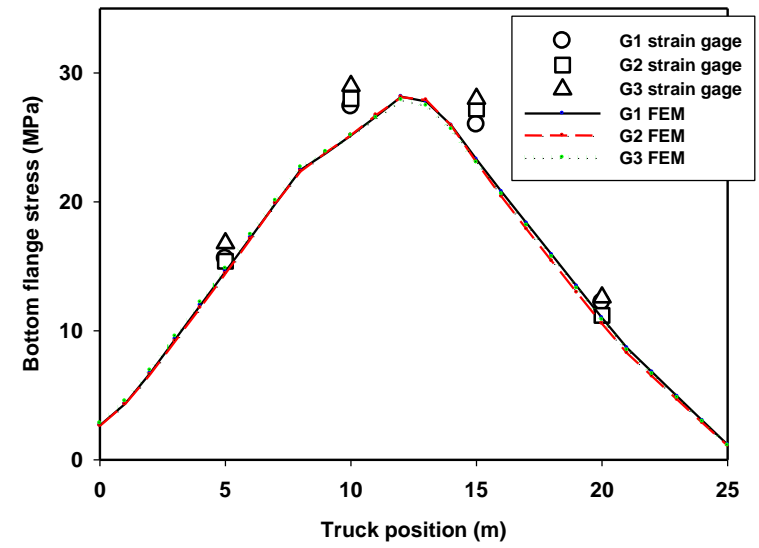

(b)

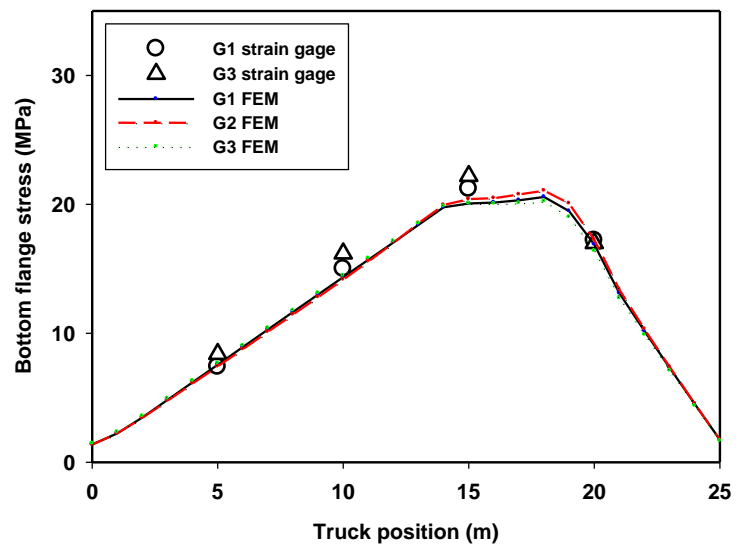

(c)

Fig. 5. Comparison between global model results and measured stain data for longitudinal bottom flange stresses at (a) quarter span (b) midspan, and (c) three quarter span.

Table 1. Variations of bridge parameters in the parametric study.

\begin{tabular}{lcccc}
\hline Parameter & $\begin{array}{c}\text { Span length } \\
(\mathbf{m})\end{array}$ & $\begin{array}{c}\text { Girder Spacing } \\
(\mathbf{m})\end{array}$ & $\begin{array}{c}\text { Slab Thickness } \\
(\mathbf{m m})\end{array}$ & $\begin{array}{c}\text { Girder Stiffness } \\
\left(\mathbf{m m}^{4}\right)\end{array}$ \\
\hline & 18 & 3.0 & 240 & $1.2 \times 10^{10}$ \\
Effect of bridge & 24 & 3.0 & 240 & $1.2 \times 10^{10}$ \\
span length & 30 & 3.0 & 240 & $1.2 \times 10^{10}$ \\
& 36 & 3.0 & 240 & $1.2 \times 10^{10}$ \\
\hline & 24 & 2.1 & 240 & $1.2 \times 10^{10}$ \\
Effect of girder & 24 & 2.4 & 240 & $1.2 \times 10^{10}$ \\
spacing & 24 & 2.7 & 240 & $1.2 \times 10^{10}$ \\
& 24 & 3.0 & 240 & $1.2 \times 10^{10}$ \\
\hline & 24 & 3.0 & 210 & $1.2 \times 10^{10}$ \\
Effect of slab & 24 & 3.0 & 240 & $1.2 \times 10^{10}$ \\
thickness & 24 & 3.0 & 270 & $1.2 \times 10^{10}$ \\
& 24 & 3.0 & 300 & $1.2 \times 10^{10}$ \\
\hline & 24 & 3.0 & 240 & $1.0 \times 10^{10}$ \\
Effect of girder & 24 & 3.0 & 240 & $1.2 \times 10^{10}$ \\
stiffness & 24 & 3.0 & 240 & $1.5 \times 10^{10}$ \\
& 24 & 3.0 & 240 & $1.7 \times 10^{10}$ \\
\hline
\end{tabular}

The AASHTO standard truck HS20 was applied in the multistep analysis in the study. The truck load configuration is shown in Fig. 6. 


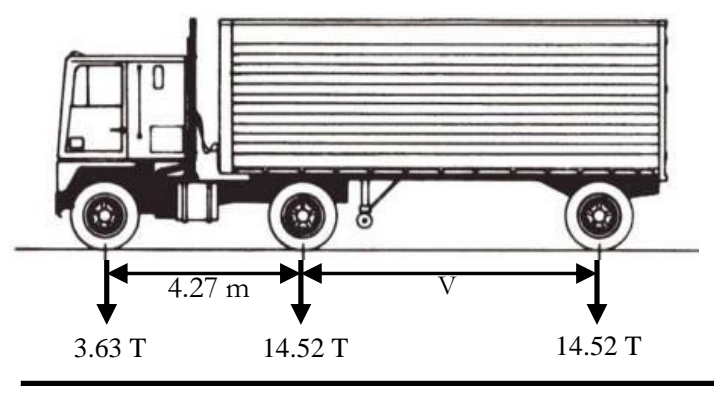

$\mathrm{V}=$ variable spacing (from $4.27 \mathrm{~m}$ to $9.15 \mathrm{~m}$ )

Fig. 6. Configuration of standard AASHTO truck (HS20-44).

Since the bridge is transversally symmetric with two lanes, two general loading types including one truck on the left lane and two trucks on both lanes are considered. Figure 7 shows possible transverse truck loading combinations for two-truck loadings. The outer-outer loading case is defined by one truck moving in the left edge of left lane and another truck on the right edge of right lane, as shown in Fig. 7(a), the center-center loading case is when both trucks move in the center of the left and right lanes, as shown in Fig. 7(b), and the inner-inner loading case is when one truck moves in the right edge of left lane and another truck on left edge of the right lane, as shown in Fig. 7(c). Other transverse loading cases including the outer-center, outer-inner, and center-inner are shown in Figs. 7(d), (e), and (f), respectively.

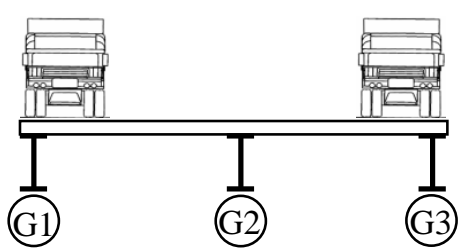

(a)

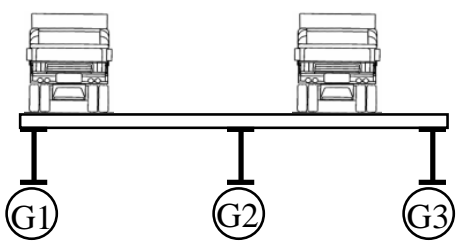

(d)

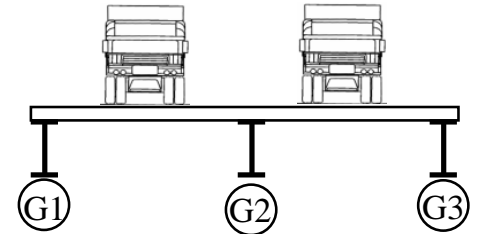

(b)

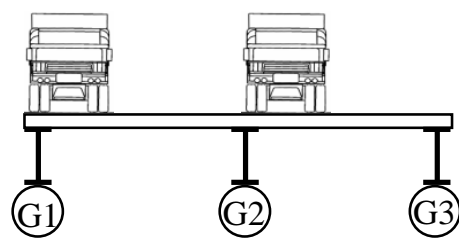

(e)

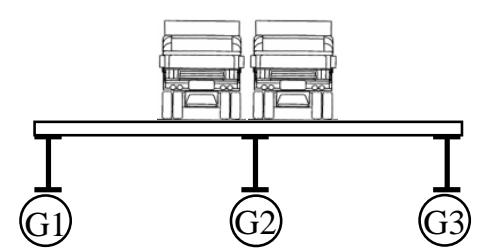

(c)

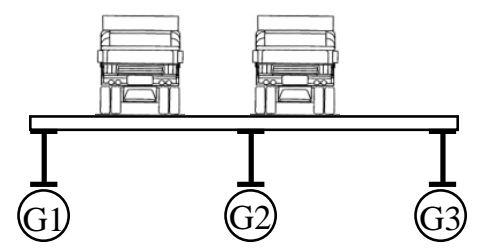

(f)

Fig. 7. Transverse truck loading combinations (a) outer-outer (b) center-center (c) inner-inner (d) outercenter (e) outer-inner (f) center-inner.

\section{Effects of Bridge Parameters on Differential Girder Deflection}

In the parametric study, the truck loading moves along the bridge at speed of $1 \mathrm{~mm} / \mathrm{s}$, and for every $0.1 \mathrm{~m}$ the bridge responses from the finite element model are recorded. After examining the vertical displacement data, the critical longitudinal truck position causing the largest girder deflection is found to be around midspan, e.g., the front wheels locate at $17.9 \mathrm{~m}$ from the support for the base case bridge. The differential deflections between adjacent girders, i.e., the difference between midspan deflections of girder G1 and girder G2, and the difference between midspan deflections of girder G2 and girder G3, are also largest at this critical truck position for both one-truck and two-truck loadings.

For the one-truck loading, the largest differential deflection between adjacent girders occurs when the truck moves along the left edge of left lane (outer). For the two-truck loading, the critical transversal truck position is the outer-inner configuration, as shown in Fig. 7(e). The differential deflection between girders 
G2 and G3 is higher than that between girders G1 and G2. The effect of each bridge parameter will be discussed in the following sections.

\subsection{Effects of Span Length}

Figure 8 shows the maximum differential deflections between adjacent girders as a function of bridge span length. Obviously, the differential girder deflection increases as the bridge span length increases. Figure 8(a) shows the results for the case of one-truck loading. At any bridge span length, the maximum differential deflection between girders G1 and G2 (under loaded lane) is almost identical to that between girders G2 and G3. The maximum differential deflection occurs when the truck is on the left edge of the left lane (outer of the lane).

Figure 8(b) shows the results for the maximum differential deflection in the case of two-truck loading. The critical transverse truck position is outer-inner combination. In the case of two trucks, the differential deflection between girders G2 and G3 is higher than that between girders G1 and G2. Comparing Fig. 8(a) with Fig. 8(b), it is apparent that the differential displacement under one-truck loading is more critical than that under two-truck loading.

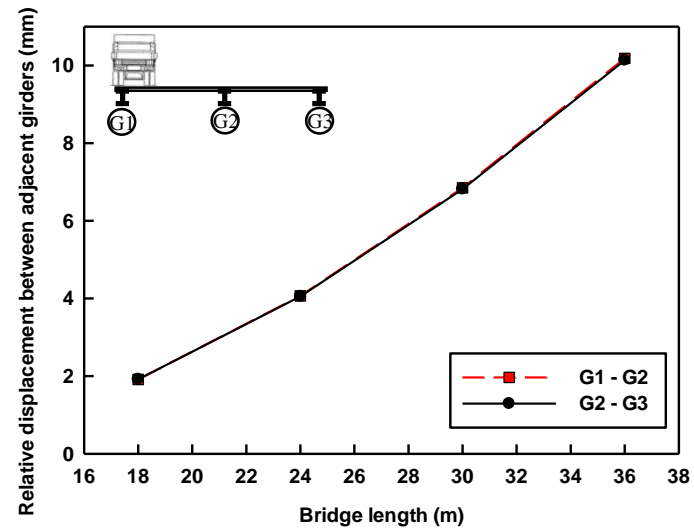

(a)

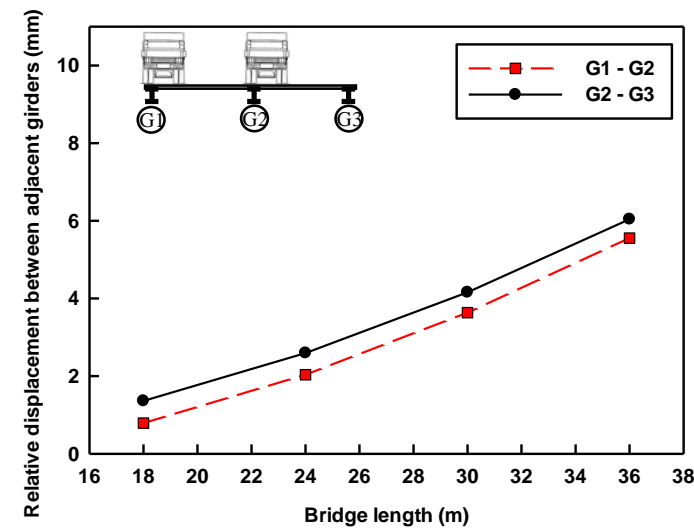

(b)

Fig. 8. Effect of bridge span length on differential deflection (a) one truck (b) two trucks.

\subsection{Effects of Girder Spacing}

Figure 9 shows that the maximum differential deflections between adjacent girders as a function of the girder spacing. As the girder spacing increases, the length of the diaphragm increases, thus, reducing the diaphragm stiffness and resulting in the increase of differential deflection. For the case of one-truck loading, the difference between differential deflections of girders G1 and G2 (under loaded lane) and girders G2 and G3 is insignificant, as shown in Fig. 9(a).

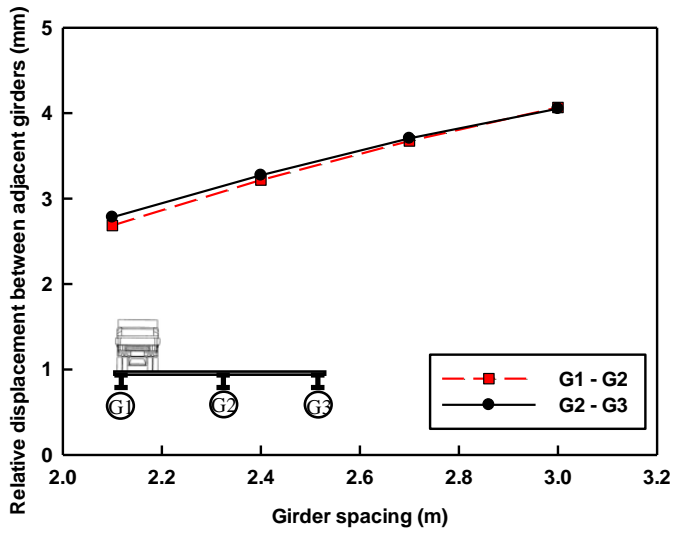

(a)

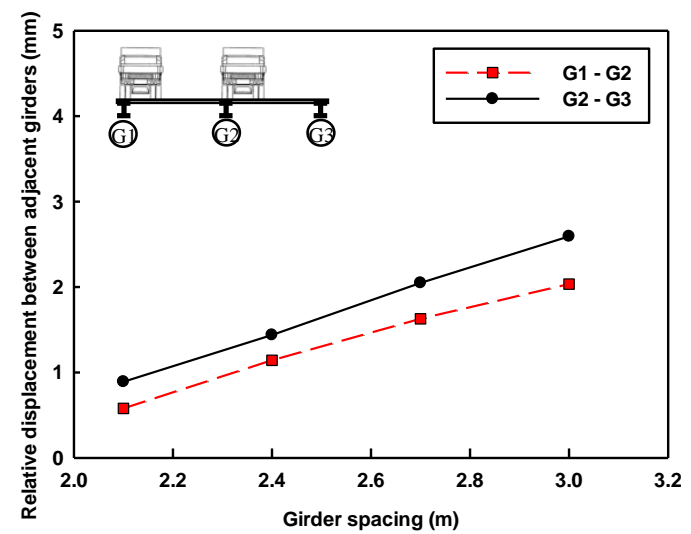

(b)

Fig. 9. Effect of girder spacing on differential deflection (a) one truck (b) two trucks. 
In the case of two trucks, as shown in Fig. 9(b), the differential displacement between G2 and G3 is higher than that between G1 and G2. Again, the maximum differential deflection under two-truck loading is lower than that under one-truck loading.

\subsection{Effects of Slab Thickness}

Figure 10 shows that the differential deflection decreases as slab thickness increases and comparison of both loading cases shows that one truck-loading is more critical than two-truck loading. Increasing the slab thickness increases the rigidity of slab; therefore decreasing the deflection of the girders. The slab improves the lateral load distribution and integrity of the girder system. Figure 10(a) shows that the differential deflections between girders under loaded and unloaded lanes are similar in the case of one-truck loading.

In the case of two trucks, the differential deflection between girders G2 and G3 is higher than that between girders G1 and G2, as shown in Fig. 10(b).

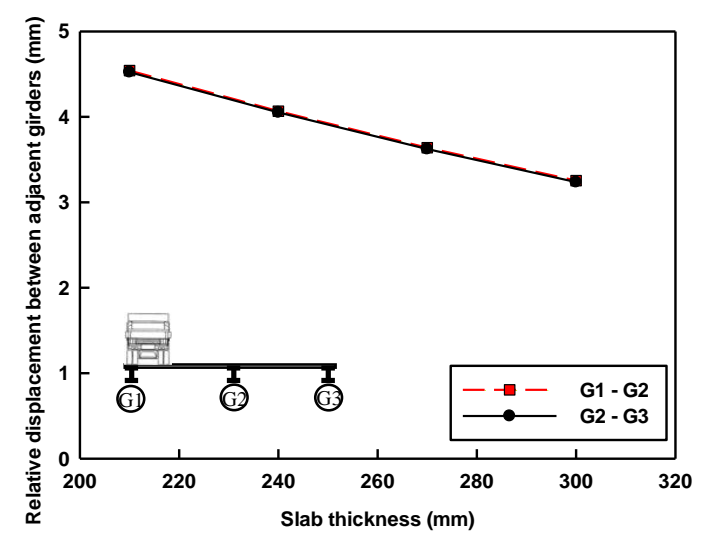

(a)

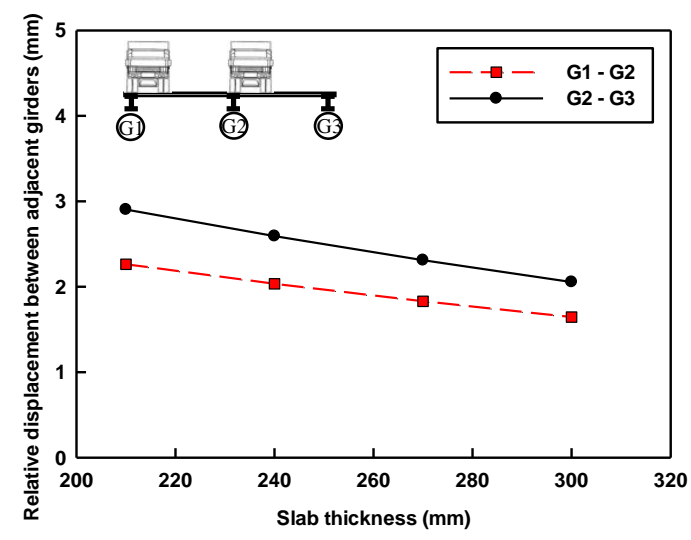

(b)

Fig. 10. Effect of slab thickness on differential deflection (a) one truck (b) two trucks.

\subsection{Effects of Girder Stiffness}

As shown in Fig. 11, the differential deflection between adjacent girders decreases as the girder stiffness increases. In the case of one-truck loading, Fig. 11(a) shows that the differential deflections between adjacent girders are similar. For the two-truck loading, Fig. 11(b) shows that the outer-inner case is a critical case, and the differential deflection between girders G2 and G3 is higher than that between girders G1 and G2. One-truck loading causes higher differential deflection between adjacent girders than two truck-loading.

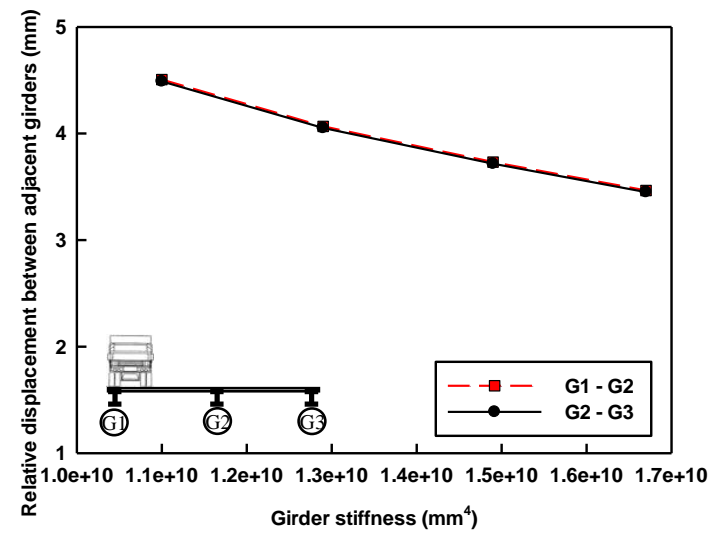

(a)

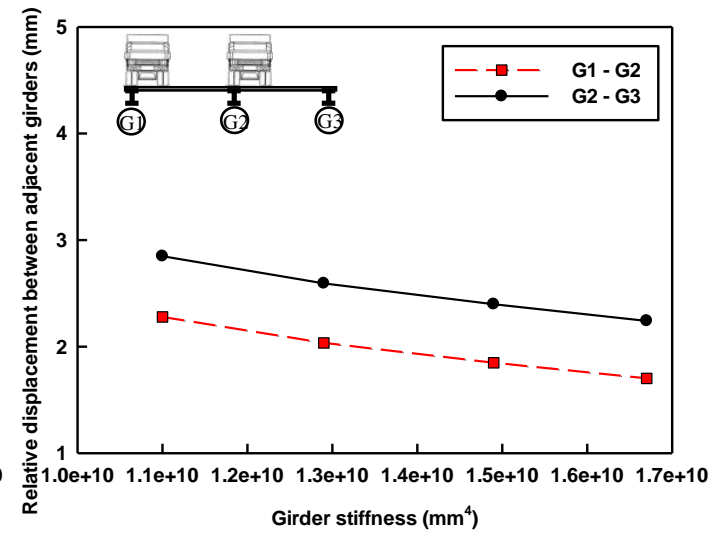

(b)

Fig. 11. Effect of girder stiffness on differential deflection (a) one truck (b) two trucks. 


\subsection{Ranking of Influencing Bridge Parameters}

Figure 12 plots the percentage change of differential deflection between adjacent girders with the change of each bridge parameter relative to the base case value. This facilitates ranking bridge parameters on their influence on the differential girder deflection. Positive slope means the differential deflection increases with the increase of bridge parameter and vice versa. Steeper line (larger absolute value of slope) means that the differential deflection between adjacent girders is more sensitive to the change of the parameter thus the effect of the corresponding parameter is larger, and vice versa.

For one-truck loading case shown in Fig. 12(a), the slopes from linear regression analysis show that the most influential bridge parameter is the bridge span length followed by girder spacing and slab thickness, while girder stiffness is the least influential one among the four bridge parameters. Similarly, for two-truck loading case shown in Fig. 12(b), the differential deflection between adjacent girders is most sensitive to the change in bridge span length followed by girder spacing, slab thickness, and girder stiffness.

In Figs. 12(a) and 12(b), similar influence of bridge parameters for both truck loading cases is observed. The effects of bridge parameters on differential deflection between girders G1 and G2 and that between girders G2 and G3 are almost identical, except for the effect of bridge span length under two truck-loading in which the slope corresponding to G1-G2 is slightly larger than that corresponding to G2-G3. For the effect of girder spacing, the regression line slope in Fig. 12(a) is slightly shallower than that in Fig. 12(b). Therefore, the effect of girder spacing on differential deflection is more notable for two-truck loading case than for one truck-loading case.

Consequently, the bridge parameters affecting differential deflection between adjacent girders in descending order are the bridge span length, girder spacing, slab thickness, and girder stiffness.

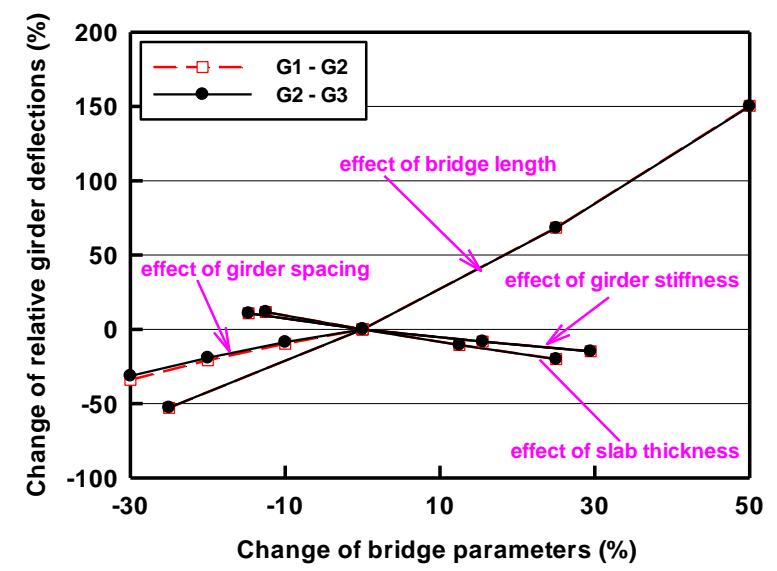

(a)

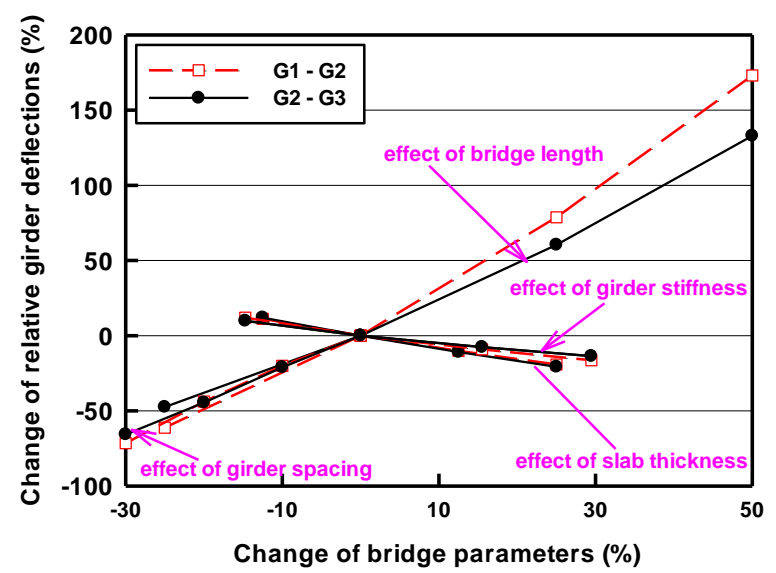

(b)

Fig. 12. Ranking of bridge parameters for differential deflection (a) one truck (b) two trucks.

\section{Effects of Bridge Parameters on Distortion-Induced Web Gap Stresses}

By applying the differential deflection calculated from the global model to the refined finite element model, the sub-model, the peak web gap stress can be investigated. Figure 13 shows the midspan transverse section of the bridge before and after deformation under one-truck loading. A typical vertical stress contour in the web gap area, as shown in Fig. 14(a), demonstrates that the stress field decays rapidly in both longitudinal and vertical directions away from the end of stiffener. It is observed from stress distribution in the web gap area for all sub-models that the critical vertical stress occurs either at the top of web gap near the end of stiffener or at the bottom of web gap near bottom flange, as shown in Fig. 14(b). The web gap stress is then taken as the larger value from these two positions. 

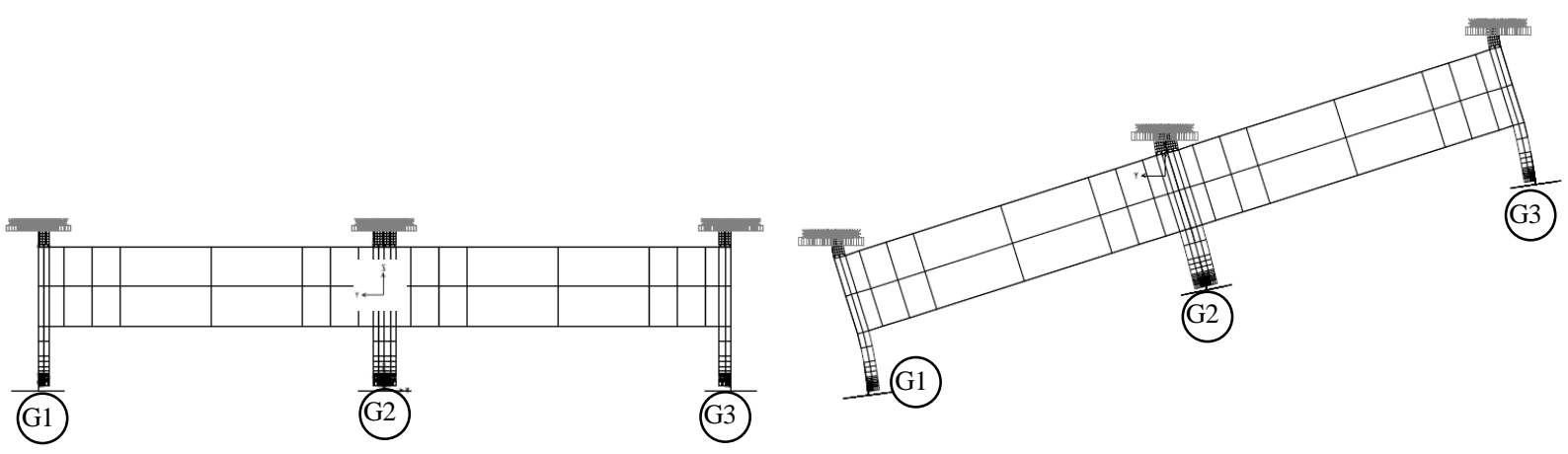

Fig. 13. Midspan transverse section (a) undeformed shape (b) deformed shape.

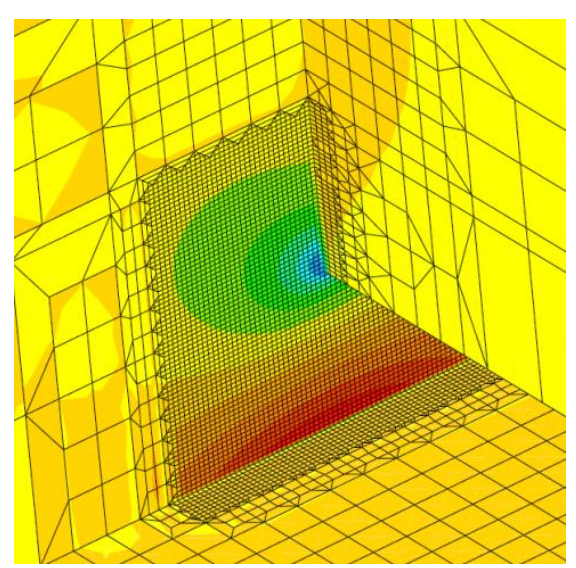

(a)

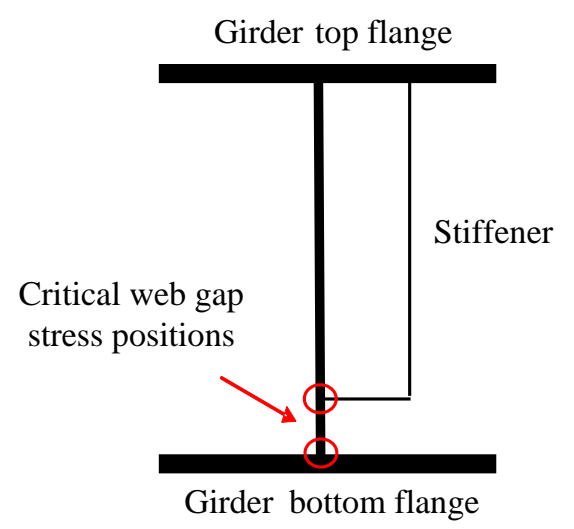

(b)

Fig. 14. Web gap vertical stress distribution (a) typical stress contour (b) critical positions.

\subsection{Effects of Span Length}

Figure 15 shows the critical web gap stress as a function of bridge span length. Obviously, the web gap stress increases as the bridge span length increases. In the case of one-truck loading, the critical web gap stress occurs at the end of stiffener of girder G2, while in the case of two-truck loading, the critical web gap stress occurs in the area near the bottom flange of girder G3. Similar findings are observed for other bridge parameters. For the case of one truck, the maximum web gap stresses in girders G2 and G1 are higher than that in girder G3. Because the differential deflection between girders G2 and G3 is larger than that between girders G1 and G2, the web gap stresses in G2 and G3 are higher than that in G1 for the case of two trucks. Similar to the differential deflection, the critical vertical web gap stress resulted from one-truck loading is higher than that from two-truck loading.

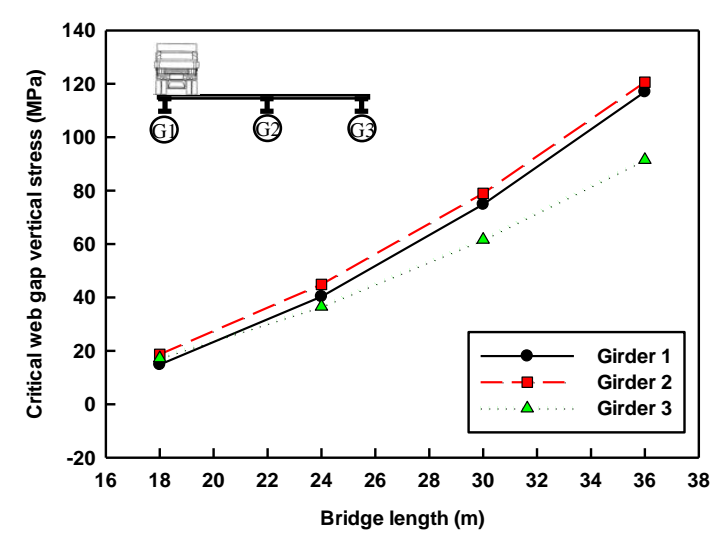

(a)

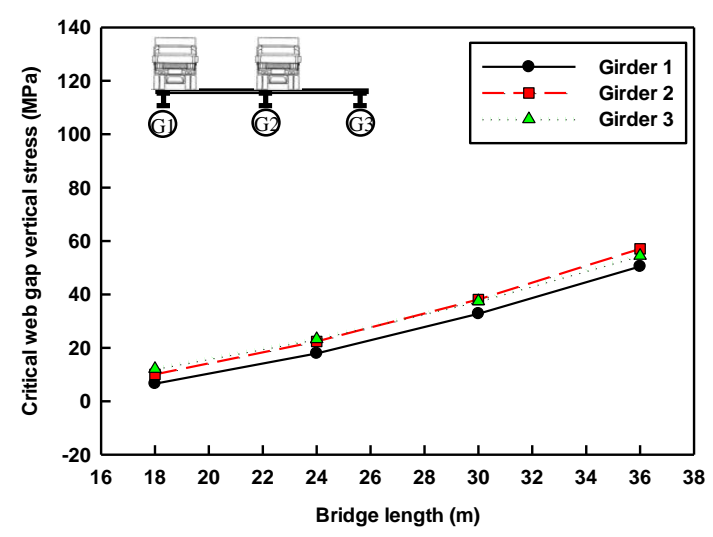

(b)

Fig. 15. Effect of bridge span length on distortion-induced stress (a) one truck (b) two trucks. 


\subsection{Effects of Girder Spacing}

Figure 16 shows the maximum web gap stress as a function of girder spacing. Figure 16(a) shows that the increase of maximum web gap stress is minimal as the girder spacing increases. This implies that the rotation of diaphragm, i.e., the differential deflection divided by girder spacing, remains almost the same for different girder spacing values under one-truck loading. This observation is in accordance with Jajich et al. $[7,11]$ where the web gap stress is determined by the rotation of diaphragm instead of differential deflection.

For the two-truck loading case, the maximum web gap stress increases as the girder spacing increases, as shown in Fig. 16(b), and the critical web gap stress in G2 and G3 are higher than that in G1. Overall, the critical web gap stress caused by one-truck loading is higher than that caused by two-truck loading.

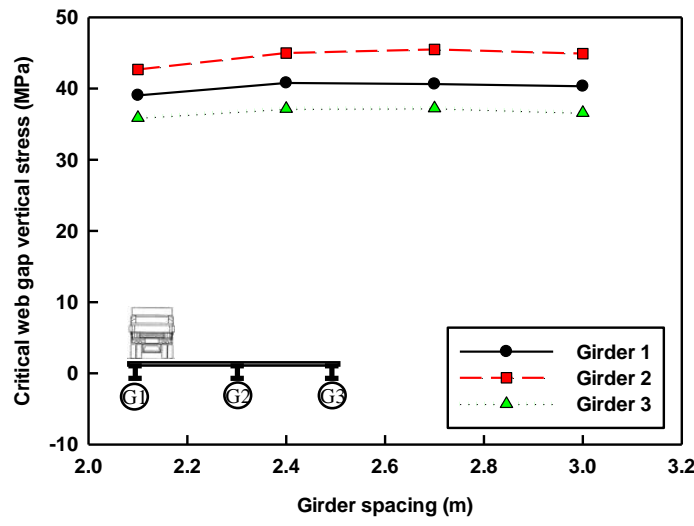

(a)

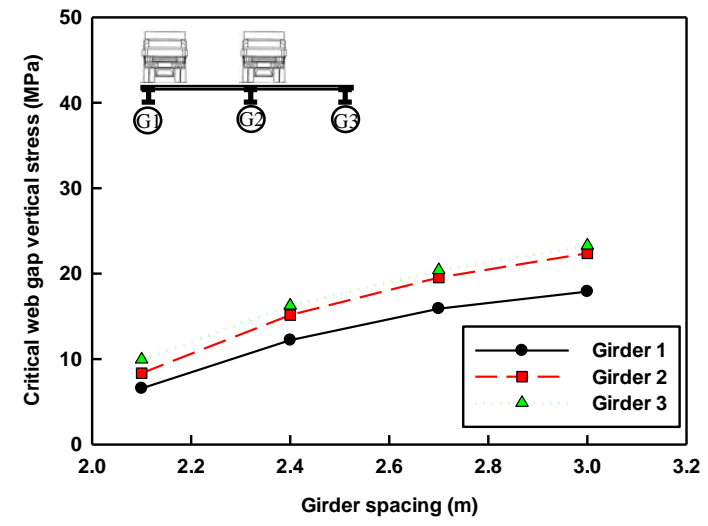

(b)

Fig. 16. Effect of girder spacing on distortion-induced stress (a) one truck (b) two trucks.

\subsection{Effects of Slab Thickness}

As shown in Fig. 17, the maximum web gap stress decreases as slab thickness increases. For one-truck loading, Fig. 17(a) shows that the maximum web gap occurs in G2. As the differential deflection between G2 and G3 is higher than that between G1 and G2, the web gap stress in the G2 and G3 are higher than that in G1, as shown in Fig. 17(b) for two-truck loading. Comparison between two loading cases shows that the vertical web gap stress under one-truck loading is more critical than two-truck loading.

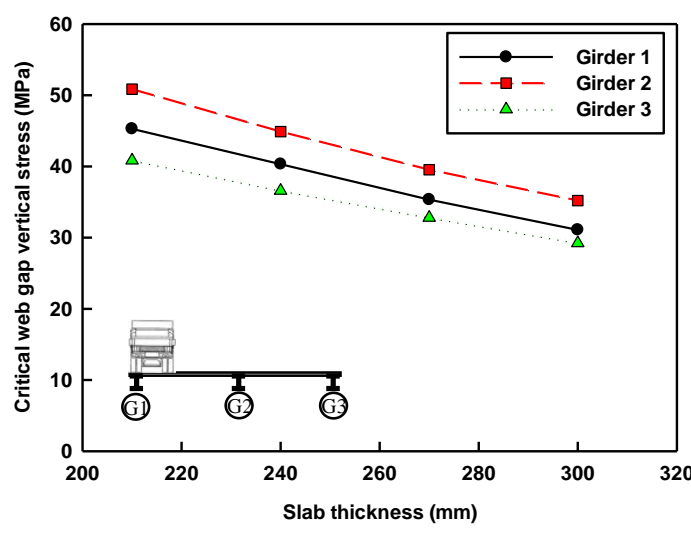

(a)

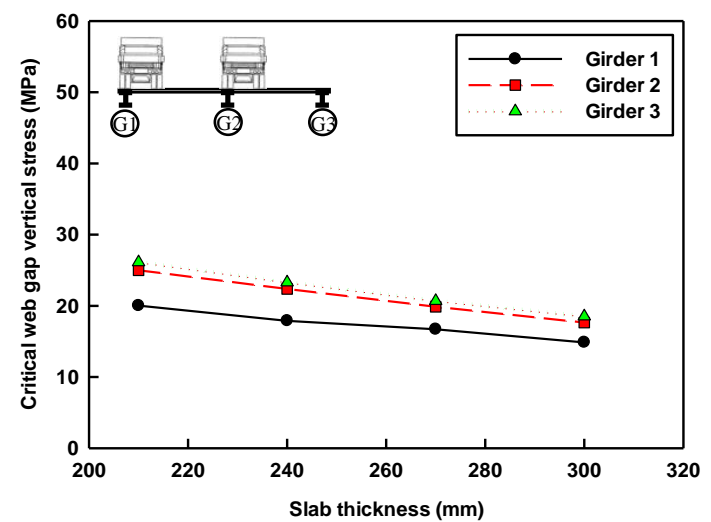

(b)

Fig. 17. Effect of slab thickness on distortion-induced stress (a) one truck (b) two trucks. 


\subsection{Effects of Girder Stiffness}

As the main girders become stiffer, both differential deflection between adjacent girders and maximum web gap stress decrease, as shown in Fig. 18. The web gap stress is further decreased as the web gap area becomes stiffer since the thickness of both web and flanges are increased with the increase of girder stiffness in the parametric study. For one-truck loading case, the maximum web gap stress in G2 is the largest followed by G1 and G3.

Figure 18(b) shows the results for the case of two-truck loading. The maximum web gap stresses in G2 and G3 are identical and higher than G1. This can be attributed to the fact that the differential deflection between G2 and G3 is larger than that between G1 and G2. Moreover, the critical web gap stress resulted from one-truck loading is higher than that from two-truck loading.

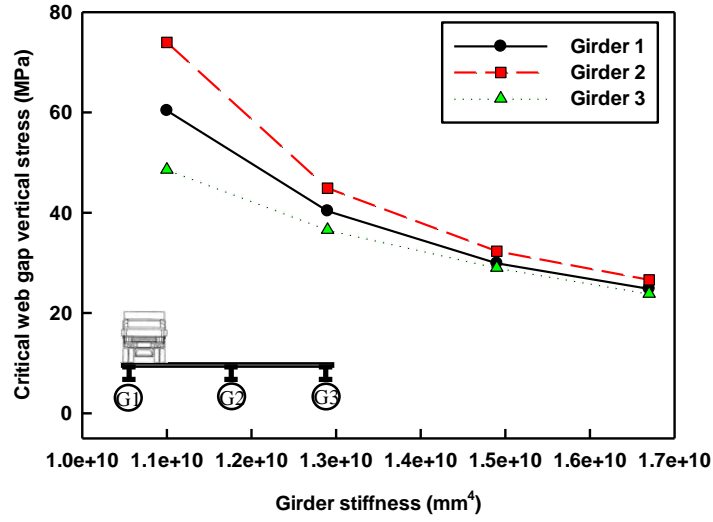

(a)

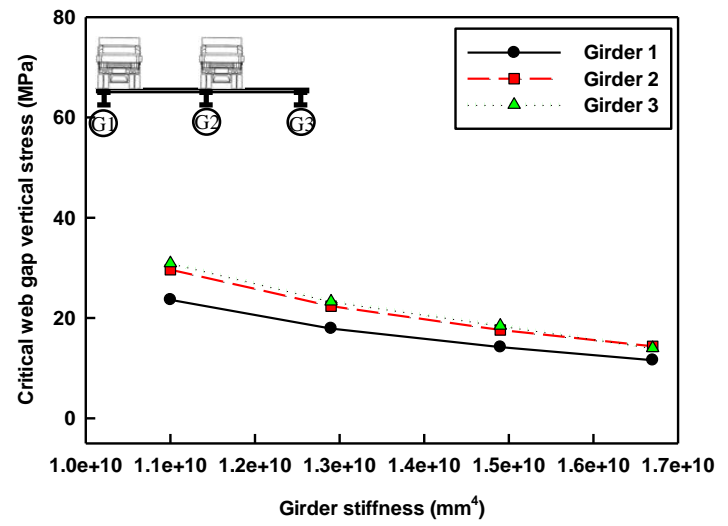

(b)

Fig. 18. Effect of girder stiffness on distortion-induced stress (a) one truck (b) two trucks.

\subsection{Ranking of Influencing Bridge Parameters}

Similar to the ranking of bridge parameters on the differential girder deflection described in Section 3.5, the parameters are normalized by relative percentage of change from the base case value. The effects of changing these parameters on the change of maximum web gap stresses are shown in Fig. 19(a) and Fig. 19(b) for one-truck and two-truck loading cases, respectively.

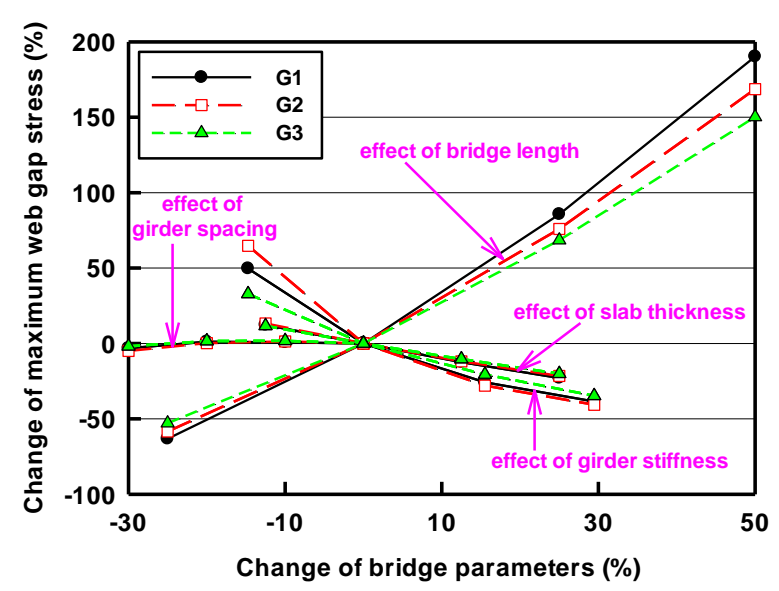

(a)

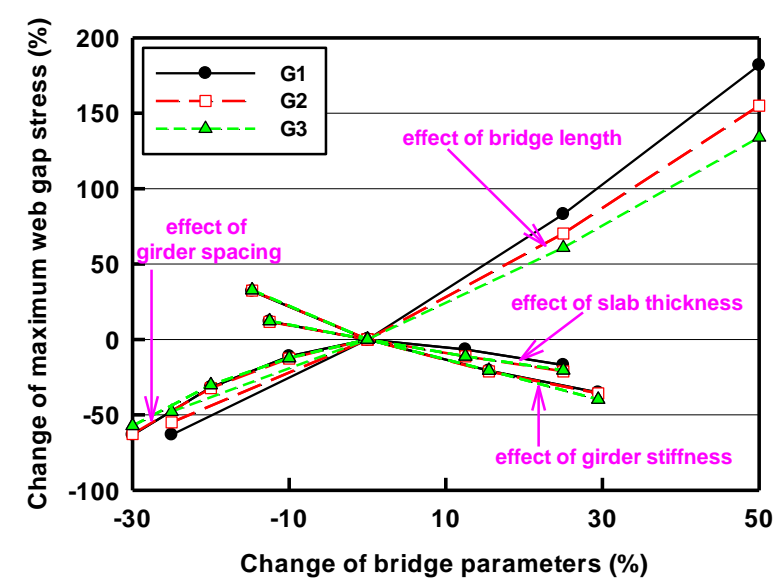

(b)

Fig. 19. Ranking of bridge parameters for distortion-induced web gap stress (a) one truck (b) two trucks.

Some lines in Fig. 19 can be best fitted by a quadratic polynomial, however, for the purpose of ranking the sensitivity of web gap stress to the bridge parameters, linear regression analysis (with $\mathrm{R}^{2}$ not less than $0.9)$ are adopted. For the case of one-truck loading, the most influential parameter affecting web gap stress 
is the bridge span length, followed by girder stiffness, slab thickness, and girder spacing. Unlike the differential girder deflection, the maximum web gap stress is more sensitive to the change in girder stiffness. In the finite element analysis, the variation in girder stiffness is accomplished by varying thickness of girder flanges and web. For the case of two-truck loading, the most influencing bridge parameter is the bridge span length followed by girder spacing, girder stiffness, and slab thickness.

Table 2 summarizes the bridge parameter rankings for their influence on the differential girder deflection and critical web gap stress for one-truck and two-truck loading cases.

Table 2. Summary of bridge parameter rankings on differential girder deflection and web gap stress.

\begin{tabular}{lcccr}
\hline Degree of & \multicolumn{2}{c}{ Differential Deflection } & \multicolumn{2}{c}{ Critical Web Gap Stress } \\
Influence & One Truck & Two Trucks & One Truck & Two Trucks \\
\hline most influential & Span length & Span length & Span length & Span length \\
& Girder spacing & Girder spacing & Girder stiffness & Girder spacing \\
& Slab thickness & Slab thickness & Slab thickness & Girder stiffness \\
least influential & Girder stiffness & Girder stiffness & Girder spacing & Slab thickness \\
\hline
\end{tabular}

Distortion-induced stress is influenced by differential deflection between adjacent girders [1]. From Section 3 and 4, both differential deflection and web gap stress increase with increasing span length and girder spacing, while decrease with increasing slab thickness and girder stiffness. However, the effects of each bridge parameter on differential deflection and web gap stress are not consistent. For differential deflection, the bridge span length is the most influential parameter followed by the girder spacing, slab thickness and girder stiffness. While girder stiffness is the least influential parameter for differential deflection, it plays a more important role on the critical web gap stress as the web thickness is changed implicitly in the finite element model. In addition, the girder spacing may not affect the critical web gap stress under one-truck loading as long as the rotation of diaphragm remains almost constant.

Results from sub-model finite element analysis show that the web gap deforms as a double curvature shape. Both rotation and lateral displacement occur at both web gap ends. Therefore, Eqs. (1) and (2) that consider only rotation or lateral displacement of the web gap ends can be oversimplified.

\section{Conclusions}

Dual-level finite element analyses incorporating both global model, which encompasses the entire bridge superstructure, and sub-model, which encompasses a portion of bridge superstructure surrounding the studied stiffener, are performed to investigate the effects of various bridge parameters on the differential girder deflections and distortion-induced web gap stresses. The chosen bridge parameters include the bridge span length, girder spacing, slab thickness, and girder stiffness. From the parametric study, it can be concluded as follows:

- The differential girder deflection increases as the bridge span length and girder spacing increase. In contrast, it decreases with increasing slab thickness and girder stiffness. For one-truck loading, the maximum differential deflections between adjacent girders under loaded lane and unloaded lane are similar.

- For two-truck loading, the critical truck transverse position is the outer-inner combination and the critical differential deflection occurs between girders G2 and G3.

- The differential deflection between adjacent girders caused by one-truck loading is more critical than that caused by two-truck loading.

- The most influential bridge parameter affecting the differential girder deflection is the bridge span length followed by girder spacing and slab thickness. The girder stiffness is the least influential one among the four bridge parameters.

- The maximum vertical web gap stress increases as the bridge span length and girder spacing increase, while it decreases with increasing slab thickness and girder stiffness.

- Under one-truck loading, the maximum web gap stress occurs at the interior girder (G2). Under twotruck loading, the critical girders are G2 and G3.

- The web gap stress caused by one-truck loading is more critical than that caused by two-truck loading. 
- The most influential parameter affecting the web gap stress is the bridge span length followed by girder stiffness, slab thickness, and girder spacing. Unlike the differential deflection, the maximum web gap stress is more sensitive to the change in girder stiffness.

- The differential deflection is an important factor affecting the distortion-induced stress but the effect is nonlinear. Other parameters such as web thickness and web gap length should be considered explicitly in order to establish the relationship between the distortion-induced stress and differential girder deflection.

\section{Acknowledgements}

The authors would like to acknowledge the AUN/SEED-Net program for the financial support to the study. The second author would also like to acknowledge the China scholarship council for the support during the visit at Department of Civil Engineering, Chulalongkorn University.

\section{References}

[1] J. W. Fisher, J. Jin, D. C. Wagner, and B. T. Yen, "Distortion-induced fatigue cracking in steel bridges," NCHRP Rep. 336, Transportation Research Board, Washington, D.C., 1990.

[2] American Association of State Highway and Transportation Officials, AASHTO LRFD Bridge Design Specifications, 4th ed., Washington DC: AASHTO, 2007.

[3] T. E. Cousins, J. M. Stallings, D. A. Lower, and T. E. Stafford, "Field evaluation of fatigue cracking in diaphragm-girder connections," J. Perform. Constr. Fac., vol. 12, no. 1, pp. 25-32, Feb, 1998.

[4] Y. Zhao, and W. M. K. Roddis, "Fatigue crack investigation for the Arkansas river bridge in Hutchinson, Kansas," Constr. Build. Mater., vol. 14, no. 5, pp. 287-295, Jul, 2000.

[5] K. Nishikawa, J. Murakoshi, and T. Matsuki, "Study on the fatigue of steel highway bridges in Japan," Constr. Build. Mater., vol. 12, no. 2-3, pp. 133-141, Mar, 1998.

[6] R. J. Connor, J. W. Fisher, "Identifying effective and ineffective retrofits for distortion fatigue cracking in steel bridges using field instrumentation," J. Bridge Eng., vol. 11, no. 6, pp. 745-752, Jun, 2006.

[7] D. Jajich, and A. E. Schultz, "Measurement and analysis of distortion-induced fatigue in multi-girder steel bridges," J. Bridge Eng., vol. 8, no. 2, pp. 84-91, Mar, 2003.

[8] H. Li, A. E. Schultz, "Analysis of girder differential deflection and web gap stress for rapid assessment of distortional fatigue in multigirder steel bridges," Rep. Mn/RC-2005-38, Department of Civil Engineering, University of Minnesota, Minneapolis, MN, 2005.

[9] W. M. K. Roddis, and Y. Zhao, "Finite element analysis of steel bridge distortion-induced fatigue," $J$. Bridge Eng., vol. 8, no. 5, pp. 259-266, Sep, 2003.

[10] E. M. Berglund, and A. E. Schultz, "Girder differential deflection and distortion-induced fatigue in skewed steel bridges," J. Bridge Eng., vol. 11, no. 2, pp. 169-177, Mar, 2006.

[11] D. Jajich, A. E. Schultz, P. M. Bergson, and T. V. Galambos, "Distortion-induced fatigue in multigirder steel bridges," Rep. MnDOT 2000-16, Department of Civil Engineering, University of Minnesota, Minneapolis, MN, 2000.

[12] A. Lenwari, T. Senjuntichai, T. Pinkaew, T. Thepchatri, and E. Limsuwan., "Field investigation on slab-on-gider steel bridges over intersections in Thailand," Proc. The $33^{\text {rd }}$ LABSE Symposium, Bangkok, Thailand, September 9-11, 2009, pp. 1-9.

[13] Computers and Structures, "SAP2000 Getting Started," version 7.4, Berkeley, CA: Computer and Structure Inc., 2000. 
